\title{
Physique Evaluation on the Students of Huanghuai College
}

\author{
Teng-Fei Yao, Zu-Hua Xie, Qiong Zhou, Jiang-Hua Li* \\ Key Lab of Training, Monitoring and Intervention of Aquatic Sports of General Administration of Sport of China, Institute of \\ Physical Education, Jiangxi Normal University, Nanchang, China \\ lijianghua8@sina.com
}

\begin{abstract}
The aim of this paper is to evaluate fitness of the Huanghuai College students. 5024 students and 5809 students participated in this evaluation in 2014 and in 2015, respectively. The tests of body mass index, seat body flexion and $50-\mathrm{m}$ run were carried out for all the subjects; the tests of pull-ups and 1000-m run were only carried out for the male students; and the tests of $800-\mathrm{m}$ run and sit-ups were only carried out for the female students. After comparisons with the Chinese National Constitutional Health Standard of College students, we found: (1) The body composition was normal for most of the students, although a small number of male students were overweight or obese; compared to the data in 2014, the number of overweight or obese was significantly decreased in 2015. (2) Upper limb strength of the male students and waist strength of the female students were both weak for most of the students; and the data in 2015 were worse than the data in 2014. (3) Performances of the subjects in tests of $50-\mathrm{m}$ run and seat body flexion were satisfactory, but the excellent rate was not high. (4) Performances of the subjects in middle-distance running were bad, and failure rate in 2015 was significantly increased compared to that in 2014.
\end{abstract}

Keywords-Huanghuai college; fitness test; physique monitoring; student; physical education

\section{INTRODUCTION}

According to the "Sixth National Student Physical Health Survey”, physical fitness of the college students tested in 2012 was getting better than those college students tested in 2006 . They have better strength and explosive strength, and significantly improved flexibility, endurance and other physical qualities. The results also show that the physical condition of our young students has improved. A new era of good nutritional supplement made the students' morphological indices significantly improved [1]. Cardiopulmonary function level also appeared on the rise; however, hi in excellent, some college students in the school lack of exercise and regular nutritional supplement, resulting in the speed, power quality decline, endurance and explosive power also declined, lack of exercise is leading to the emergence of obesity and overweight, this phenomenon had to arouse our attention, students in school, not only to learn professional knowledge, building blocks for the country, but also should exercise a good body, so as to enter the community, to adapt to high-pressure, fast-paced work, follow the pace of the times, a useful human society [2]. In order to carry out the "National Fitness Program" and "National Student Physical Health Standard", this article through the Huanghuai College 2014 and 2015 levels of new students for physical testing, a comprehensive understanding of college students just entered the physical condition, so that physical fitness test data to quantify, purposefully study the law of college students physical fitness, scientific guidance to students during college health training for the Huanghuai College to take measures to intervene, how to cultivate sports talent to provide a reasonable scientific basis.

\section{SUBJECTS AND METHODS}

\section{A. Subjeces}

In 2014 and 2015, all the new Huanghuai College students (except the Department of Physical Education) were recruited to participate in the "National Student Physical Health Standard Test”. In 2014 a total of 5024 students participated in physical fitness test, including 2481 male and 2543 female; in 2015 a total of 5809 students, including 2732 male and 3077 female, participated in the relevant physical fitness test.

\section{B. Methods}

By accessing CNKI, Chinese Journal Full-text Database of Wanfang Database, Chinese Excellent Doctoral Dissertation and Full-text Database of Chinese Excellent Master's Degree Dissertations, 56 domestic papers and 56 papers have been reviewed in recent years, among which there are 7 dissertations. Through the registration of education and sports official website, as well as the use of Baidu and other search engines to collect relevant policy documents and implementation of the dynamic.

"Chinese National Physical Health Standard of College Students" was used as a standard for the evaluation on the students in Huanghuai College. The data tested and collected according to standard testing method of Chinese National Physical Health test. Microsoft Excel 2010 and SPSS 19.0 were used for data statistics and analysis.

\section{RESUltS AND DISCUSSION}

\section{A. Body mass index}

Height weight index refers to the proportion of height and weight should be in the normal range, which by height and weight of a certain proportion of relationships, reflecting the body's circumference, width and thickness and density. Height and weight is an important index to evaluate human body's morphological development level and nutritional status and body symmetry, which is of great significance to evaluate the body's uniformity, growth and nutrition status. Meanwhile, the 
physiological function, physical quality and movement Ability to have a significant impact [3].

Height and Body Mass Index (BMI) test is a method to assist in the determination of body composition. Height the Body Mass Index reflects the condition of the individual's body composition. Height Body Mass Index $(\mathrm{BMI})=$ weight $(\mathrm{kg}) /$ [height (m) ${ }^{2}[4]$.

TABLE I. BODY COMPOSITION DISTRIBUTION IN 2014

\begin{tabular}{|c|c|c|c|c|c|}
\hline Gender & Number & $\begin{array}{c}\text { Under } \\
\text { weight }\end{array}$ & $\begin{array}{c}\text { Normal } \\
\text { weight }\end{array}$ & $\begin{array}{c}\text { Over } \\
\text { weight }\end{array}$ & Obesity \\
\hline Male & 2481 & $17.69 \%$ & $56.55 \%$ & $19.55 \%$ & $6.21 \%$ \\
\hline Female & 2543 & $11.84 \%$ & $78.14 \%$ & $7.00 \%$ & $3.03 \%$ \\
\hline
\end{tabular}

As can be seen from Table I, in the 2014 women's BMI frequency can be found in the light weight of the female or occupy a certain percentage. Can be seen, girls pay attention to body at the same time, ignoring the physical health problems. The male of the low weight and overweight ratio is relatively high, in order to prevent underweight and overweight, obesity, these two unhealthy body, so through physical exercise, increase the amount of activity and some other methods conducive to physical fitness Improve their physical condition.

TABLE II. BODY COMPOSITION DISTRIBUTION IN 2015

\begin{tabular}{|c|c|c|c|c|c|}
\hline Gender & Number & $\begin{array}{c}\text { Under } \\
\text { weight }\end{array}$ & $\begin{array}{c}\text { Normal } \\
\text { weight }\end{array}$ & $\begin{array}{c}\text { Over } \\
\text { weight }\end{array}$ & Obesity \\
\hline Male & 2732 & $10.47 \%$ & $69.73 \%$ & $15.26 \%$ & $4.54 \%$ \\
\hline Female & 3077 & $8.68 \%$ & $84.99 \%$ & $5.49 \%$ & $0.84 \%$ \\
\hline
\end{tabular}

From Table II, it can be seen that male have a lower proportion of normal body weight than female, while underweight and overweight are more prevalent than female.

Compared with height and weight data of male and female in Huanghuai College in 2014 and 2015, the proportion of students with low weight and overweight has decreased significantly, while the proportion of students with normal BMI has obviously increased.

\section{B. Seat body flexion}

Physical development by a variety of factors, including genetic, environmental, nutrition, nature of work and acquired exercise are affected. The complexity of body composition and the regularity of the growth and development of living bodies determine the diversity of factors affecting the development of the body [5]. Physical fitness refers to the human body in the completion of the exercise process shown by the strength, speed, endurance, sensitivity, flexibility and other functional capabilities. The level of physical fitness not only with individual muscle anatomy, physiological characteristics, but also with the human body's energy supply and the level of function of the system, in particular, the nervous system regulation have a great relationship. In addition, but also with the genetic factors, gender, age characteristics, the nature of work and other closely linked.

The flexion of the sitting position is mainly the range of activity that the trunk, waist and hip joints can achieve under the quiescent state of the students, mainly reflecting the stretching and elasticity of the joints, muscles and ligaments and the development level of the students [6].

TABLE III. PERFORMACE IN SEAT BODY FLEXION TEST IN 2014

\begin{tabular}{|c|c|c|c|c|c|}
\hline Gender & Number & Excellent & Good & Pass & Failed \\
\hline Male & 2481 & $13.83 \%$ & $19.43 \%$ & $59.13 \%$ & $7.62 \%$ \\
\hline Female & 2543 & $18.32 \%$ & $25.05 \%$ & $50.49 \%$ & $6.13 \%$ \\
\hline
\end{tabular}

From Table III, we can see that the new students of 2014 are more flexible, but most of the students are in the pass line, especially the male. The female' excellent rate and good rate are higher than those of the male.

TABLE IV. PERFORMACE IN SEAT BODY FLEXION TEST IN 2015

\begin{tabular}{|c|c|c|c|c|c|}
\hline Gender & Number & Excellent & Good & Pass & Failed \\
\hline Male & 2732 & $10.98 \%$ & $25.33 \%$ & $58.49 \%$ & $5.20 \%$ \\
\hline Female & 3077 & $15.63 \%$ & $25.54 \%$ & $55.25 \%$ & $3.57 \%$ \\
\hline
\end{tabular}

As can be seen from Table IV, Huanghuai College 2015 students sitting body flexion level is generally good, but from the data to see the difference between male and female is not great, female sitting body flexion score slightly better than male.

From the above two tables can be seen, Huanghuai College 2015 new students than the 2014 level of new students has increased, but the excellent rate of male and female have declined.

\section{50-m run}

50 - $\mathrm{m}$ run is a typical project, reflects the body's ability to move quickly is an indicator used to test the physical displacement speed. $50-\mathrm{m}$ run results can be integrated to reflect the flexibility of the neural process, the body's coordination, joint and muscle flexibility and muscle strength and endurance.[4]

TABLE V. PERFORMACE IN 50-M RUN TEST IN 2014

\begin{tabular}{|c|c|c|c|c|c|}
\hline Gender & Number & Excellent & Good & Pass & Failed \\
\hline Male & 2481 & $9.96 \%$ & $7.01 \%$ & $70.82 \%$ & $12.21 \%$ \\
\hline Female & 2543 & $14.51 \%$ & $12.58 \%$ & $61.70 \%$ & $11.21 \%$ \\
\hline
\end{tabular}

As shown in Table V, 2014, there are $87.79 \%$ of male and $88.79 \%$ female $50-\mathrm{m}$ run scores in passing, most of the results are up to pass the level, male score relatively poor, in the range of relatively large number of people passing, and male and female students excellent rate of $14.51 \%$, respectively, and female higher rate of excellence. 
PRESS

TABLE VI. PERFORMACE IN 50-M RUN TEST IN 2015

\begin{tabular}{|c|c|c|c|c|c|}
\hline Gender & Number & Excellent & Good & Pass & Failed \\
\hline Male & 2732 & $8.16 \%$ & $6.81 \%$ & $74.23 \%$ & $10.80 \%$ \\
\hline Female & 3077 & $17.29 \%$ & $11.96 \%$ & $57.10 \%$ & $13.65 \%$ \\
\hline
\end{tabular}

As can be seen from Table VI, 2015 newborn male good rate and good rate is relatively low, while female are pass rate is low, the failure rate of the gap between men and women is not.

Through two years of data show that 2014 class and 2015 class male and female students excellent rate and good rate are little changed, but the failure rate is a decline in male, female have risen.

\section{Pull-ups and sit-ups}

Pull-up is to overcome the body weight of their power of drape practice. It requires students to have a certain grip strength, upper limb strength and shoulder strap strength; this force must be able to overcome their own weight to complete once. Pull-up force on the development of upper limb drape, shoulder strap strength and grip strength plays an important role.

The sit-ups test is one method of evaluating muscle strength and endurance. Because it can safely test muscle strength and endurance, while doing sit-ups is mainly abdominal muscle at work, hip muscles are also involved in the work, so this test not only assess the endurance of the abdominal muscles, but also reflects the hip muscle endurance.

TABLE VII. PERFORMACES IN PULL-UPS AND SIT-UPS TESTS IN 2014

\begin{tabular}{|c|c|c|c|c|c|}
\hline Gender & Number & Excellent & Good & Pass & Failed \\
\hline Male (pull-ups) & 2481 & $3.39 \%$ & $6.17 \%$ & $26.60 \%$ & $63.85 \%$ \\
\hline Female (sit-ups) & 2543 & $2.20 \%$ & $5.82 \%$ & $65.79 \%$ & $26.19 \%$ \\
\hline
\end{tabular}

As can be seen from Table VII, male and female have a lower rate of excellent, male pass up the pass rate is lower, situps higher rate of female sit-ups, most students are distributed in passing and failing grades fluctuate.

TABLE VIII. PERFORMACES IN PULL-UPS AND SIT-UPS TESTS IN 2015

\begin{tabular}{|c|c|c|c|c|c|}
\hline Gender & Number & Excellent & Good & Pass & Failed \\
\hline Male (pull-ups) & 2732 & $0.55 \%$ & $2.05 \%$ & $20.24 \%$ & $77.16 \%$ \\
\hline Female (sit-ups) & 3077 & $0.94 \%$ & $0.49 \%$ & $63.18 \%$ & $35.39 \%$ \\
\hline
\end{tabular}

As can be seen from Table VIII, 2015 male’ pull-ups and female' sit-ups good rate and good rate of $2.6 \%$ of all students, $1.53 \%$, male pull up only $20.24 \%$ pass rate.

Table 9 and Table 10 show that in 2014 and 2015, the male lead-up test scores failed most, and in 2015, the percentage of failing male rose by $13.13 \%$ compared with 2014 , and the passing rate continued to decline trend.

Female sit-ups, in the sit-up test in 2015, excellent rate and good rate decreased by $1.26 \%$ over the previous year, $5.33 \%$, pass rate is not much change, failing rate increased by $9.2 \%$ over the previous year, results also declined the trend of.

\section{E. Middle-distance run}

As can be seen from Table IX, male students in the middledistance run excellent performance rate is higher than female, passing rate is lower than female, but the failure rate is higher than female.

TABLE IX. PERFORMACES IN MIDDLE-DISTANCE RUN IN 2014

\begin{tabular}{|c|c|c|c|c|c|}
\hline Gender & Number & Excellent & Good & Pass & Failed \\
\hline Male $(1000-\mathrm{m})$ & 2481 & $9.47 \%$ & $10.68 \%$ & $61.95 \%$ & $17.90 \%$ \\
\hline Female $(800-\mathrm{m})$ & 2543 & $7.90 \%$ & $10.93 \%$ & $68.54 \%$ & $12.62 \%$ \\
\hline
\end{tabular}

As can be seen from Table X, only male in 2015 the rate of better than female, good and pass rates are not as good as female, and the failure rate is not much difference between female.

TABLE X. PERFORMACES IN MIDDLE-DISTANCE RUN IN 2015

\begin{tabular}{|c|c|c|c|c|c|}
\hline Gender & Number & Excellent & Good & Pass & Failed \\
\hline Male $(1000-\mathrm{m})$ & 2732 & $7.91 \%$ & $5.89 \%$ & $70.97 \%$ & $15.23 \%$ \\
\hline Female $(800-\mathrm{m})$ & 3077 & $5.95 \%$ & $6.14 \%$ & $72.77 \%$ & $15.14 \%$ \\
\hline
\end{tabular}

From the above two years of data can be seen, male and female students in the excellent middle-distance run rate, good rate decreased, compared to male, female performance decreased faster, and male in the middle-distance run rate is increased.

\section{CONCLUSIONS AND RECOMMENDATIONS}

\section{A. Conclusions}

Through the analysis of the body shape, physical function and physical fitness of the students in Huanghuai College in 2014 and 2015, the statistics and analysis showed that:

The BMI index of most male students in Huanghuai College in 2014 and 2015 is with normal weight, but in 2014 and 2015 , the percentage of male out of the normal weight is $25.76 \%$ and $19.80 \%$ respectively, and the percentage of nonnormal weight has decreased. Female BMI index is ideal.

In 2014 and 2015, the proportion of students passing the 50 -meter run has reached $80 \%$, the scores are relatively good, but most of them are near the passing line.

In 2014 and 2015, the pass rate of male in Huanghuai College is lower. female sit-ups in 2014 a very small number of female in the excellent range; $73.81 \%$ of female in the qualified range; a considerable part of the female in the failing range, and in 2015 the passing rate of only 64.61\%, compared with the previous year of the decline.

In 2014 and 2015, the pass rate of male pull-up is 36.15\% and $32.84 \%$ respectively, which was the worst among the test items of "National Students 'Constitutional Health Standard", which indicated that the male' upper limb strength was seriously insufficient and should be paid great attention by teachers . Strength of the upper limbs to enhance the training through a variety of ways, and the process of strength training is boring, so to enrich the means of upper body strength 
training, so that students are not easy to accept boring, and thus the overall development of physical fitness.

Male $1000-m$ run results in $2014,82.1 \%$ of students in the qualified range, in $201584.77 \%$ of students in the pass range, passing rate increased to a certain extent. Female $800-\mathrm{m}$ run project test results in 2015 the number of failed percentage of less than 2014 failed to $2.52 \%$ of the proportion of low, excellent test scores and good results in the number of students tested low. To improve performance in middle-distance run, we must improve the speed of the endurance quality of teaching, endurance quality training, gradually increase the intensity of training load. In the teaching, teachers should encourage students to enhance self-confidence, to stimulate students' inner potential.

The five indicators of the best students in the seat body flexion pass rate and good rate is relatively high, but the excellent rate is not high, and showing a very obvious difference between men and women, male generally poor flexibility, indicating that male in the flexible quality of the exercise should be more concerned about the project. Update the concept, to strengthen due to gender differences caused by weak quality of exercise.

\section{B. Recommendations}

Make full use of the resources of elective courses, vigorously develop the physical fitness of students, according to the characteristics of different options for different students in accordance with their aptitude, to carry out various forms of project, stimulate student interest, so that students fully feel the sport of the happy, comprehensive exercise all aspects of the physical fitness of students, thereby fully improve the health of college students. For students of cardiopulmonary exercise, should increase the amount of aerobic exercise in the course of the various options; for female waist strength, lower limb strength, to add local small muscle training in the course content [7]; male upper limb strength weak, the need for strength Sexual training content, these are the future in physical education teaching methods to improve.

Students urge the formation of a good lifestyle, and guide them to recognize all kinds of unreasonable factors exist in their own way of life, and ultimately encourage them to voluntarily correct poor eating habits and behavior, and truly recognize the scientific way of life to improve their the importance of physical health level [8].
Physical enhancement is a cumulative process, the current college students less physical education per week, to enhance physical fitness is far from enough schools should use the existing space for students to provide physical exercise sites and facilities, open all types of sports Management, and appropriate organization of various forms of extra-curricular sports activities and competitions, and promote the development of campus culture, improve the physical health of students.

\section{ACKNOWLEDGMENT}

This work was supported by the Open Project Program of Key Lab of Training, Monitoring and Intervention of Aquatic Sports of General Administration of Sport of China, Jiangxi Normal University (NO. 201604).

\section{REFERENCES}

[1] T.H.Li. Comparative Study on Physical Health of Freshmen in Jilin Institute of Physical Education in Recent Three Years[D].DaLian, Liaoning Normal University,2012

[2] Z.F.Yang and C.F.Li, An Analysis of the Results of the National Student Physique and Health Standard of Hechi University in 2012[J]. Journal of Gansu Lianhe University (Natural Sciences),6th ed.vol.27,2013,pp.62-70.

[3] G.F.Li and Z.Z, Research on the Exploitation of College Physical Education Curriculum Resources and the Standards of Students' Physical Constitution and Health[J]. Journal of Hubei Sports Science,4th ed.vol.31,2012,pp.451-452.

[4] Y.yao. "An Analysis of the Test Results of "National Students' Constitutional Health Standard" in Suzhou University" [D].SuZhou,Suzhou University,2012

[5] G.Q.Jiang, A Study on the Factors Affecting the Achievement of National Student Constitution Health Standard [J]. Jilin Institute of Physical Education,4th ed.vol.27,2011, pp. 99-102

[6] R.B.Yang and P.H.Zhao. The Physique Condition of Girl Students Enrolled in Universities from Taiyuan University of Technology [J]. Journal of Beijing Sport University,5th ed.vol.28, 2011, pp. 647-648

[7] J.Wen and S.L.Zhao, Investigation and Analysis of Students 'Physical Health in Hangzhou Teachers' College[J]. Journal of Hangzhou Normal University,1st ed.vol.5,2013,pp. 68-71.

[8] F.Chen, Results of the 2010 National Student Physical Fitness Survey[J].Chinese Journal of School Health,9th ed . vol. 32, 2010, pp. 1025-1026. 